\title{
President's Letter
}

\author{
Anna-Maria Rollin
}

$\mathrm{L}$

OOKING at an advance copy of the programme for the annual BARNA Conference $(17 \& 18$ June 2004), I was struck by the broad range of topics and speakers. The clinical topics include haemodynamic monitoring, acute pain, fluid replacement therapy, infection control, paediatric anaesthesia, cardiorespiratory emergencies and anaesthetic drugs. The management topics cover people management, a nurse-led PACU, the government's 'Agenda for Change', clinical competencies, medico-legal matters, patient power, national occupational standards and health care assistants. There are clinical scenarios and workshops, ranging from lifepreserving skills like advanced airway management to New Age skills like reflexology. The speakers include nurses, patients, anaesthetists, intensivists, ODPs, managers - and that reflexologist. Nowhere did I see a session on the ancient art of handmaidening!

This very broad range of topics and disciplines fits in well with the NHS Modernisation Programme (see Pat Smedley's article on pp 12-15). The thrust of this programme is to look at new and more efficient ways of working, to break down interprofessional and interdisciplinary boundaries where these inhibit proper team working, and to make maximum use of all the skills and talents available in a necessarily limited workforce.

Anaesthesia has always been in the forefront of the drive to team working. The nature of the work lends itself to multidisciplinary teams, and as long ago as 1998, the Association of Anaesthetists of Great Britain and Ireland published a booklet called 'The Anaesthesia Team', laying out the basic principles (The Anaesthesia Team, London). Things have changed a great deal since then, but the concept is perhaps even more valid and more vital, in the light of continuing staff shortages, than ever.

Nurses are interwoven into the anaesthesia team at every point. Preoperative assessment, once the province

Correspondence to: Anna-Maria Rollin, President, Epsom General Hospital, Dorking Road, Epsom, Surrey KT18 7EG, UK of half trained and reluctant junior surgical staff, has increasingly been seen as a nurse-led activity. Where nurse-led clinics have been established, working in close cooperation with the anaesthetists who will be giving the anaesthetics, there has been a fall in cancellations, and shorter hospital stays. Harder to quantify, but no less important, has been a fall in the number of patients who are operated upon in a less than optimal state, because the necessary investigations have not been done, but the anaesthetist has been reluctant to cancel on the day of surgery, with all its attendant inconvenience and distress.

The journey from the ward to the operating theatre may be short, but can be nerve-racking for the patient. The presence of a familiar nurse may make all the difference, not only to the patient's state of mind, but also to the quality of the handover that will ensure that patient's safety.

The role of the anaesthetic nurse, as 'skilled and dedicated assistant' to the anaesthetist needs no explanation to the members of this Association. Except in the direst of life-threatening emergencies, no anaesthetist would contemplate embarking on any anaesthetic without such an assistant.

Similarly, there is no longer any need whatsoever to argue the case for specially trained and dedicated recovery nurses. An interesting recent innovation has been the development of nurse-led Post Anaesthesia Care Units (PACUs). Of course, there have always been robust recovery room sisters who ruled their domain with a rod of iron, and who gave short shrift to any surgeon or anaesthetist who dared step out of line. However, there is now a formalisation of this informal 'pilot scheme' in a number of places and it will be interesting to see the results of the formal assessments when they appear. I am confident of good results.

After the recovery phase, most hospitals now have acute pain teams, many led by and most incorporating acute pain nurses. Again, their value to the experience of the patient is now proven. 
As part of the Modernisation Programme, there are a number of extensions to the role of the nurse in the anaesthesia (as well as the surgical and medical) team being piloted. There is a scheme whereby nurses will be trained to administer epidural anaesthesia. As discussed in the August 2003 issue of BJARN, the Changing Workforce Programme of the Department of Health is overseeing a scheme to bring into being a new breed of professional, the Anaesthetic and Critical Care Practitioner (BJARN, 2003). It is not intended that these will simply be nurses with an extended role. However, it is a new field into which nurses may wish to venture.

There are inevitably tensions between 'multiskilling' and 'specialisation', both of them current buzzwords.
To a certain extent, they are mutually exclusive, and this tension and its effect on the numbers of people required to staff an institution must be acknowledged. However, the concepts of competency based training and the skills escalator may be part of the answer.

Competency based training will give people skills which should in many instances be transferable across specialisms. The skills escalator approach being espoused by the new NHS University is also designed to encourage life-long learning.

With all these interwoven threads crossing and recrossing, these are interesting times. The programme for the BARNA Conference reflects that. I am looking forward to meeting many of you there.

\section{REFERENCES}

The Anaesthesia Team. The Association of Anaesthetists of Great Britain and Ireland. London: August 1998
New ways of working in anaesthesia. British Journal of Anaesthetic and Recovery Nursing 2003; 4(3): 12-14 